\title{
"Pehakovia" and House Forming Strategy and To Kaili Settlement in Central Celebes Indonesia
}

\author{
Zaenal Siradjuddin \\ Architecture Department of Tadulako University, Palu, Indonesia \\ Email: ybmtondo@gmail.com
}

How to cite this paper: Siradjuddin, Z. (2020). "Pehakovia" and House Forming Strategy and To Kaili Settlement in Central Celebes Indonesia. Advances in Anthropology, 10, 1-16.

https://doi.org/10.4236/aa.2020.101001

Received: September 2, 2019

Accepted: December 2, 2019

Published: December 5, 2019

Copyright (c) 2020 by author(s) and Scientific Research Publishing Inc. This work is licensed under the Creative Commons Attribution International License (CC BY 4.0).

http://creativecommons.org/licenses/by/4.0/ (c) (i) Open Access

\begin{abstract}
In Indonesia, there are many unique settlement patterns, which reflect the customs and wisdom of indigenous tribes. The "Kaili" tribe in Central Sulawesi (To Kaili) is one of the many tribes in Indonesia who have their own principles in shaping their homes and natural environment. Some principles that become a benchmark in his life are: 1) "Hintuvu" (regulating human-human relations), 2) "Katuvua" (human-natural relationship), 3) "Pehakovia" (guardian of humans and nature or spirit). The question of his research is: How does "Pehakovia" become the foundation of spirituality to build the house and environment of the Natural "To Kaill"? This study aims to observe the role of "Pehakovia" in relation to procedures for building houses and the natural environment of To Kaili from time to time. Phenomenology methods are used to answer questions and goals. The results revealed the role of "Pekahovia" in the "To Kaili" community, ranging from the uniqueness of the settlement to the lifestyle of the "Tokaili". Phenomenological methods are also used to measure the role of Pehakovia in planning and designing homes and the surrounding natural environment. The core role of "Pekahovia" in the life of "To Kaill" is to find a balance of life in the To Kaili community. The concept of macrocosm into the concept of a microcosm concept is reflected in the application of local wisdom strategies in the home and settlement. The process of Internalization cosmological concepts in the home and environment aims to create a sense of security and avoid the possibility of disaster. The harmonious relationship between humans and spiritual guardians ("Pehakovia") is manifested by various traditional ceremonies that fill the lives of the "To Kaili" Society; this process shows the balance has occurred in the home and the surrounding natural environment.
\end{abstract}

\section{Keywords}

To Kaili Behavior, Equilibrium, Settlement, Vernacular, Architecture 


\section{Introduction}

The "To Kaili" tribe settlements in Indonesia have several phases of formation: the first primitive phase and then the traditional phase. Pre-modern phase developed into a phase of modern settlement and finally to post-modern settlement. The primitive settlement phase (Fathy, 1973) is characterized by simplicity of form, and the use of very simple technology and cultural practices that tend to meet the demands of time. In the traditional phase, there is progress as a result of the development of community culture; these developments encourage people to do Trial and Erro so as to give birth to agreed forms and become a tradition among the people. Technological developments in the pre-modern phase are influenced by developments in science and culture in society. Pre-modern influences encouraged the formation of houses and dwellings which describes habits and becomes knowledge about the procedure for building in society.

The modern phase of housing and settlement development introduces the principles of logical design to the use of manufacturing materials so that the causal relationship between form and function can be expressed as a procedure believed to meet the needs of the community at that time. This research seeks to examine developments in how to build houses and housing based on the growth of the technical and cultural capabilities of the community over time for time.

This research is aimed at observing the behavior of the "To Kaili" community, in meeting the needs of housing and housing starting from the primitive era that is nomadic and up to permanently occupying homes.

The first house was first formed when "To Kaili" still lived in a cave with a nomadic way of life, a nomadic period of 25 years before returning to its original place.

The development of nomadic life takes place over a number of periods, first between 15 and 25 years; then the second period between 5 to 15 years; then the third period between 3 until 5 years and finally the fourth period is no longer nomadic or settled permanently.

The development process of the "To Kaili" settlement is influenced by the development of knowledge and culture, which cannot be separated from three basic principles, namely: Hintuvu (human relations with humans), Pehakovia (human relations with Nature Guardian) and Katuvua (human relations with Nature).

Pehakovia in the development of houses and settlements has an important role associated with trust in the power of the Nature Guard and efforts to protect residents and settlements from various disasters (Zaenal, 2015).

Based on the description above, this study aims to reveal the role of the authority of the natural ruler behind the formation of ideal homes and settlements from time to time in the sedentary phase.

\section{Background Knowledge}

In Indonesia, the local wisdom of each tribe actually has a variety of identical conditions, so that the local wisdom they have cannot be compared to each 
community group. The literature used in this study is intended as a background for researchers' knowledge which includes: vernacular architecture, settlements, cultural canalization in society, with the aim of being the initial knowledge of researchers used to capture various phenomena in the field according to needs. From this study, the vernacular architecture is probably best understood not by what it is, but what it can reveal about the culture of the community or habits at a certain time

\subsection{Settlement}

Human settlement or settlement is defined as a place of life and a place of relationship (interaction) between humans and humans, with nature and with the authorities of nature. Thus the Settlement is a container that is filled with humans or the physical container of human habitation.

Settlement as a residence is a place or area where people gather and live together, building houses and facilities needed in human life. Settlements can also be said as a collection of houses inhabited by residents, forming a community as a place to live, work, and a place to communicate. In addition, the formation of settlements should not be described only in three dimensions, but must be seen from four dimensions, because the human element of life always changes its character and culture in units of time (Doxiadis, 1971).

There are 5 elements of the formation of settlers (Human Settlement) according to (Doxiadis, 1971), as follows:

1) Nature as an element, that is, a village place or container formed by environmental elements such as geography, topography, land, water resources, plants, animals and climate or weather. For all these elements interact so that it functions as a village or village.

2) Humans as elements, namely people who live in nature and carry out activities, such as: bio-logical activities, sensations, perceptions, emotions, and morals related to the values and norms held by humans or groups of people.

3) Community as an element, is a group of people who live together to form a residential environment, such as forming social strata, forming culture (culture), and forming administrative regions.

4) Protection (shelter) as an element, namely the structure of the container in which there are people living, such as housing, community services, business centers, recreational containers, commercial containers, offices. Network

5) Social capital as an element, namely a system that is naturally artificial and functions as a settlement, such as: Water supply systems for the needs of settlers, roads for transportation, drainage channels, communication networks, electricity networks and all other physical needs.

The five elements of settlement are aspects that must be studied holistically to find the ideal solution (Doxiadis, 1971). Village elements are assigned to maintain dynamic equilibrium, and are expressed differently in each section, at each scale and during the evolutionary process of completion. The basis of the settlement is an ecological unit that is hierarchically related to each other from each 
element. So the law of settlement is not a simple law of cause and effect, but a statistical law on the effects of change.

Settlements in the scale of residential units become cities, undergoing synchronous and diachronic changes that develop from one phase to the next. To analyze a solution, it must be connected between the past and the present. Thus the village is dynamic and changing all the time and requires new innovations to stay alive. The village will die, if it no longer provides services for human needs. Ideal settlements must provide people with comfort, security, peace and safety.

Basically, settlements are created by humans to move within the boundaries of the population, therefore settlements create physical and institutional environments. The process of change (evolution) that occurs is one of the factors that prolongs the life of settlements. The process of evolution can be analyzed by clarifying the size of the object of observation (settlements, housing units, dwellings, residential spaces) both population and area. The quality of unit relations or village securities, variations in morphogenesis, depends on the availability of physical data and non-physical factors, including social, economic, political, administrative, technological and aesthetic factors (Doxiadis, 1971).

A settlement is a residence in an environment that has a boundary or a clear area, a place consisting of "inside" and "outside" has limits to the scope of the settlement (Schulz, 1985). While the village is the result of human relations with the environment and the village serves as a center for human gathering. The village is not just a place, but it is part of a larger neighbourhood, so the village must have an element of "inside" and "outside".

Settlement is unique, and is a point of interest with an outline that is likely to be a dominant element, attracting or becoming a magnet, so that people will have an attachment that becomes a glue between them. The village has the characteristics achieved through the physical condition of the environment and non-physical conditions such as culture, social life of society is a system that has been stable and patterned in a place and related to the history of society.

Another view of settlements is part of a large region within a region, functioning as the center of a group and is an interpretation of a site, a land or a plot and transformed into a place where people live. Some environments, which have a specific natural character and spatial structure are referred to as plains, valleys, and ponds (basins), and these spaces are equipped with natural elements, e.g. topography with rocks owned, vegetation and water and equipped with a very important orientation such as the relationship between sites with light, weather and natural conditions that are part of the micro climate.

Settlements that emerged in the late 60s, defined as a guide housing and human life. Settlements present since the community recognizes the culture and coincide with the presence of civilization or human culture. The structure and form of the house is considered to be the embodiment of the cultural values of its community. Houses are sheltered or human shelter in the face of climate and weather changes (heat, cold, rain and wind). The house is called a residence because of its function as a place of rest, a place of family building, place of work, 
as well as a symbol of social status (Rapoport, 1969, 1977).

Human behavior varies and changes depending on the place where it is located. For the traditional community, the house is associated with various aspects, such as socio-cultural aspects, religion, and physical environment. Thus the house and settlement is basically a part of the territory in which there are residents residing, taking part in work activities, endeavoring, connecting with fellow settlers as a society and fulfilling various life activities (Rapoport, 1977).

\subsection{Vernacular Settlement}

The term vernacular settlement in architecture is often defined as a settlement formed without an architect. The vernacular term is defined as the local language, the local language as expressed in the previous discussion which is used to express a work of architecture of a society. Thus, in the settlement, the term vernacular settlement is used for the mention of local forms loaded with local content, such as: Loaded with elements of culture, environment including local climate embodied in the physical form of architecture such as layout, structure, detail of ornaments, ornaments as described in the previous discussion

Vernacular settlements can be understood as building a house together, in the eyes of the public as an architect who doubles as a worker. So that the community group that built the place settled gave birth to a village, which is located in the interior and more traditional, adaptive to the local customs and nature. The established community groups tend to settle in a hereditary area, thus presuming the settlement as the place of birth.

The realization of settlements as a residence with all the facilities it has a more determined on the process of formation than the residential products produced. Improving the quality of a society in one community is always based on the quality of its own carpentry technology and must apply the initiation process at every stage that is made aware of the tradition of the community, for example before the activity begins "Kenduri" or festivity done as part of the tradition. Architecture is not only a form of shape, but also in the form of social space, symbolic space, which reflects a space of creation and inhabitants in an architectural firm (Oliver, 1997).

The implementation of the settlement building process is generally determined from generation to generation or based on agreements relating to a trusted local orientation, so that the awakened will be similar although not entirely the same. The local orientation of the vernacular settlement explains three things: place, people and period (time) as their architectural form, therefore the local orientation of the settlement become the key word. Thus vernacular settlements are also called local villages or local settlements, because they can grow, develop, assimilate naturally and continue to grow to the present day.

\subsection{Vernacular Architecture}

The term vernacular in architecture is often interpreted as architecture without an architect. And local languages are also interpreted as local languages, which 
are used to refer to local forms that are loaded with local content, including cultural elements, the environment including the local climate which is manifested in physical architectural forms such as the layout, structure, and details of buildings.

Other colloquial terms refer to the local potential of building materials, local labor, and local wisdom. Vernacular also relates to primitive architecture such as in the form of shelter, spatial use, orientation, construction, natural influence and human behavior (Oliver, 1997).

Characteristics of vernacular buildings according to (Oliver, 1997) consist of: Buildings that are not supported by principles and theories, Adapting to the environment, In accordance with community capabilities (technology and economy), Describing community culture, Being open to natural resources in the environment and can always accept changes that can last a long time.

Vernacular architecture when viewed as a collection of houses and other supporting buildings that bound by the availability of resources from the environment. The shape of the house and its supporting elements are formed due to the fulfilment of specific needs and accommodate the culture that influences it. Vernacular architecture is born to a collection of people who live together and form groups (communities). Communities formed by kinship and homogeneity, Tradition become people guide to live which is passed down from generation to generation into a tradition, so that the community is called a collection of traditional societies. The community that formed the house together like the architect who doubles as a worker. The community gives birth to a village, and is located in the inland and more traditional, adapts characterized to local customs and its nature. The formed community group tends to settle down from generation to generation, thus regarding it as the birthplace (Zaenal, 2016).

The embodiment of the dwelling and all its facilities is more determined on the process than the product. People in one community are always based on their own carpentry technology, and must apply the initiation process at every stage and be made aware of the community tradition, for example before the start of the activity festivity which shows the strength of the customs ties in their life. Architecture is not only tangible form, but can form of social space, symbolic space, which reflects a space of creation and inhabitants (Oliver, 1997).

Implementation of the construction process, generally determined by hereditary or based on the agreement related to local orientation, the construction will be similar though not entirely the same. The local orientation of the vernacular architecture (vernacular settlement) describes three things, they are: place, people, and periods as a form of architecture, so that the local orientation becomes the key word and vernacular venues are called local villages, because they can grow, assimilate naturally, and continue to grow to the present.

The vernacular villages grew and were born from certain ethnic communities and ethnic traditions, so that they are always in line with cosmology, outlook on 
life, lifestyle, which have different appearance as a reflection of identity developed in an innovative, creative, syncretic and eclectic approach. anonymous, authentic, naive, primitive, rude, spontaneously popular, locally based or popular. The use of norms, customs, culture, climate, and the potential of local materials that have gained recognition are based on the long experience (trial and error) of community groups.

\subsection{The Concept of Sustainable Pragmatic Planning}

The development of pragmatic planning concept has developed very rapidly in the planning dimension, several opinions that reveal the concept of pragmatism, including expressing the influence of US pragmatic philosophy on the development of theory about the nature, purpose, and method of planning. Describes the key contributions of pragmatic and "neo-pragmatic" philosophers and identifies the influence of pragmatism on the initial concept of planning as a rational process; on the perspectives of Friedman, Lindblom, and Schon; on the development of the "critical pragmatism" of Foresters; and on the contribution of other planning theories in the 1980s and 1990s. Identify the importance of pragmatic ideas in emphasizing the planning dimension as a practical social learning activity, which must utilize human capacities and promote the ability to transform critical transformative systemic work in the public sphere (Healey, 2009).

The philosophical position of pragmatism acf a conceptual scaffold for design thinking. Contributing a number of existing contributions to the design has been drawn from the concepts of pragmatism. The line of thought with a broader examination of how the central concept of design thinking resonates with John Dewey's pragmatic philosophy. The argument presented suggests that there is a great degree of convergence between pragmatic perspectives and design thinking. Pragmatism offers a well-developed and coherent articulation of the crucial concerns for designing pragmatic thoughts and perspectives that can be of value at the theoretical and practical level. At the theoretical level, he can inform and inspire the development of discourse on design. At a practical level, pragmatic concepts can be operationalized to inform and guide concrete designs and help us understand and manage the design process (Dalsgaard, 2014).

Decoding thoughts can obscure the construction of a holistic and actionable paradigm of holistic planning paradigm in an attempt to develop sustainability planning that makes many approaches to sustainable development planning and policy. The dichotomy is a classic thing that was recognized more than a century ago by the hard-thinking and soft-minded William James pragmatic philosopher, or for that matter, those who believe in more and better information to overcome the challenge of sustainability and those who rely on power. Of some votes, he then argues that the approach to sustainable development is based on a philosophy of pragmatism as a means to connect a hard and gentle perspective to planning, policy and sustainability action. After detailing how the hard-minded 
and gentle temperament among sustainability supporters translate into different types of understanding and initiative, a pragmatic framework for holistic sustainability planning and a proposed policy suite. This framework is arguably based on an understanding of pragmatic theories of truth and rationality, integration and the basis of processes in action, and human experience as a test of public values and priorities for action. This opinion contributes to the evolving that refers to pragmatic philosophy, attributing this to the more work in environmental philosophy that highlights the usefulness of pragmatism in building a philosophy of sustainable development. If planners and members of a democratic society can work towards a common understanding that it is a continuous process of communication and interaction between citizens and experts who need to be sustained in the push toward sustainable development, that knowledge must be generated and tested in public. Context, and that the story has stood side by side with scientific models and statistics, an important step towards sustainability can be done in the overall planning profession (Holden, 2008).

\section{Method}

This research uses qualitative method with phenomenology approach which has stages and way of analysis as follows:

\subsection{Research Stages}

The research was carried out in several stages, namely: the mini tour stage and the Grand stage tour stage. Mini tour stage is carried out to reveal the phenomenon of the influence of "Pehovia" in the Kaili community. On the basis of the phenomena that were carried out deepening aimed at finding a PAKAKOVA issue in building a residence or a house and a "To Kaili" settlement, to find the phenomenon of the role of "pehakovia", an unstructured interview was then conducted on respondents who were considered to have knowledge about it. The determination of respondents is carried out by rolling up to find data that is deemed saturated by after the data is deemed saturated, then the researcher carries out the process of categorization and reduction so that several themes are found.

Which can explain the relationship between "Pehakovia" and the ideal process of building houses and settlements from time to time.

\subsection{Analyzing Stages}

The process of analyzing phenomena using a variety of saturated data forms the basis of truth in this study. The truth process is related to the researcher's awareness process. Such awareness consists of objective awareness used in tracing initial phenomena, then identification awareness is used to find themes, and correlation awareness is used to reduce themes to concepts and institutional awareness that is used to build concepts to form institutions or institutions. This study aims to reveal the role of Pehakovia in developing the concept of macro- 
cosm and microcosm in the home and surrounding environment.

\section{Result and Conclusion}

In the early stages of the founded phenomenon of pehakovia in the form of beliefs that reveal about the universe. Nature of the universe consists of three, the upper realm which is the place of the presiding of the ruler of nature, the middle realm is believed to be the place where humans live their lives and the lower realm as a spirits realm who have the potential to bring disaster for humans. This universe of the universe is described as the head, body and feet; this is in line with the culture of austronesia that affects the people in various islands in Indonesia (Simanjuntak, 2008).

The further study toward the phenomenon of Pehakovia found a manifestation of the application of To Kaili's belief in human life relating to the symbolization of the region, so that the belief of To Kaili states that the top of the mountain as a representation of nature over and as a place of residence of the ruler of their ancestors spirit. The summit of the mountain consists of: Wanangiki as the peak of the mountain peak, the wana as the primary forest that surrounds the peak and is a forest that should not be touched by humans, Pangale as transitional forest and humans can enter the territory to harvest the nature bounty or to hunt but not destroying the forest, so that this forest can be interpreted as a source of their protein, all these areas are then interpreted as a positive forbidden area see Figure 1.

The middle area is divided into "pahawapongko" which is a human area that is allowed to process by taking wood products and other products to be used to build houses and other living necessities as long as they are not used as a place to live. Nature is being identified with the space in which humans develop life consisting of "Pahawapongko" and "Oma". In the middle of nature (Oma) there are three categories namely: "Oma Ntua" as the first place for Kaili to settle, "Oma Ngiki" is the development of mobile life (nomadic), and in this region already has the form of a house they call it "Torowau" and "Bamaruncamali", then" Oma Nguku "is a semi-nomadic phase which is marked by changes in the house called Bolawo and Bolanoa, while when they settle they occupy lower areas that were previously believed to be limited or negative areas room and called "Balingkae", they began to form houses and houses evolved into "PabuhuHampua" and "PabuhuDola", this development was followed by the development of houses

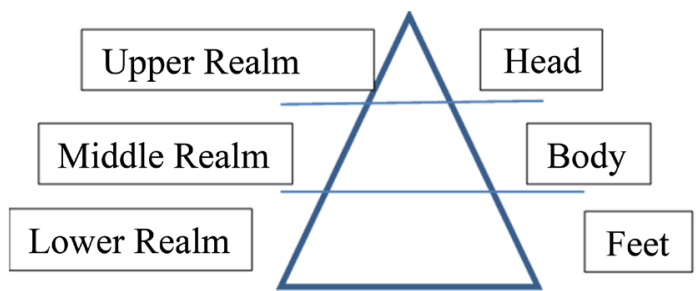

Figure 1. To Kaili definition of nature of universe. Source: Researcher analytical conclusion 2017. 
into a group of houses (Sou, Tambi) and then into villages (Boya), village settlements (Ngata) and large villages (Ngata Bete).

Based on the findings above revealed several themes such as the theme of kinship, the theme of marriage, the theme of the distribution of assets, the theme of cosmology, the theme of houses and settlements, the theme of customary rules, after undergoing the process of reduction, the resulting theme consisted of three main themes consisting of the theme of cosmology, and settlements, and custom themes or Vaya rules, which then become three concepts.

Three conceptual findings are the core of the discussion that can reveal the relationship between humans and the Guardians of Nature in relation to the formation of houses and the settlement of To Kaili from time to time, an explanation of the concept is explained as follows:

\subsection{History of the Concept of Cosmology to Kaili}

In its development it shows that one of the basic principles of life that forms/finds a point of balance is expressed by the belief in the guardians of nature that give life and protect To Kaili from various calamities. The conviction is poured into the belief in the existence of three realms consisting of, the upper realm, the middle realm and the lower realm, which are the basis for understanding the concept of cosmology to Kaili.

The concept of cosmology which consists of macro concepts of the cosmos and micro cosmos is expressed through the understanding of nature above and is believed to be a place for the spirits of their ancestors who in their lives are respected and provide virtue to others, while nature is believed to be a place where humans meet their needs and nature Under what is believed to be the place of ancestral spirits that were rejected due to his actions during his lifetime always cause damage. These three realms are categorized as components of the macro-cosmos. This concept affected the lives of the Kailis who then internalized it into a smaller life called the microcosm.

The concept of micro cosmos in To Kaili's understanding is To Kaili's attempt to apply life patterns to smaller environments, for example into houses, villages, settlements and large villages belonging to ToKaili, the application of the concept of micro cosmos is reflected in each residential unit from house to large village. The formation of the sacred space which is believed to be a micro-scale ruler of nature is the implementation of the upper nature of the macrocosm and the sacred space and is believed to protect To Kaili from disasters and protect To Kaili from disturbing spirits around them. As in a building, usually there is a place that is used to place objects that are believed to be able to ward off the entry of spirits or disasters into the house so that its inhabitants avoid disaster (Zaenal, 2014) see Figure 2.

\subsection{Concept of House, and Settlement}

Observing the growth and development of the pattern of settling to "To Kaili" 


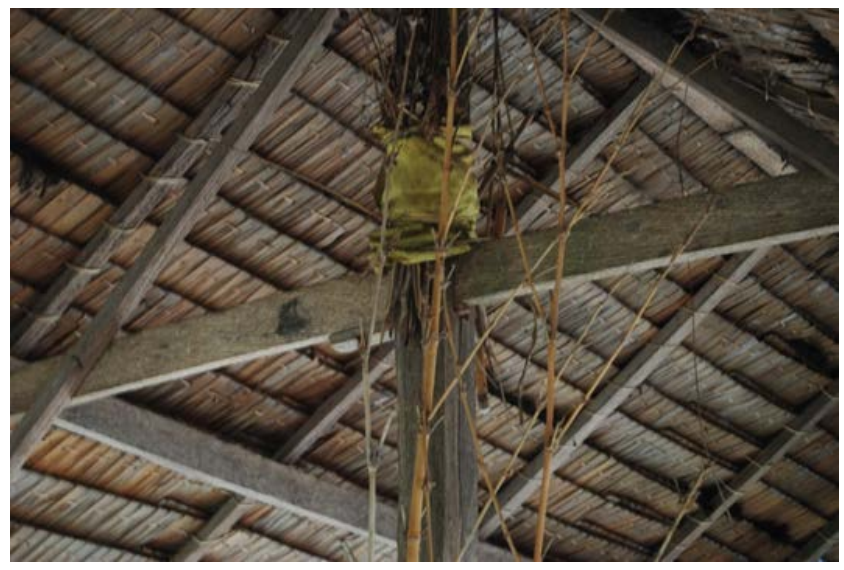

Figure 2. Some ranti wood is believed to prevent To Kaili from disaster. Source: Researchers' 2013 documentation.

which shows that the house was formed through several stages of development. namely: When "To Kaili:" still ran their nomadic life, there were three nomadic stages, namely when in "Oma Ntua", "To Kaili" did not yet have sufficient knowledge and culture in building houses, stone pits, caves or trees made temporary places, when they were in "Oma Ngiki", To Kaili then came to know a shelter in the form of "Torowau" or a shelter consisting of four pillars which were then given two sticks of wood as a leaf cover to form a space that allowed To Kaili to take shelter, while in "Oma Ngiki" also developed shelter which they call "bamaruncmali", this place is the development of "torowau" which has bale-bale made of wood, as a place of rest. This is where the embryo will form a home and become a main shelter and become part of the understanding of the universe. The birth of the cosmological concept adopted by ToKaili continued to follow the principle of macrocosm. While at the last stage of the nomadic life of "To Kaili", they occupy the middle natural boundary with the lowest realm believed to be the source of disaster. Here they build a social network among themselves in an effort to build defenses and agree on the establishment of a gathering place to perform rituals with the aim of fortifying and warding off or protecting their communities from disasters that might come as a result of spirit anger called by the building they call Bola.

In the third stage of nomadic life, "Bola" which was originally formed as a gathering place then functions as the seat of their leader (Totua), the term "Totua" or elder person. At the beginning of its development, "Totua" was a parent who led their children while living a nomadic life and at one time "Totua" wanted them to be together, then formed a group of houses where each child was made by their parents and they were united there.

"Tokaili" began to form a group of houses consisting of Bola as a residence for Totua and also functioned as a place to conduct joint rituals while other houses were called "Bolanoa". Before the formation of "Bolanoa" family group meetings were held in Bola so that family gathering time was relatively short, but when "Bolanoa" was formed for each child, gathering time was relatively longer, this is 
where the semi-nomadic process began to take shape.

"The bola" is a single bear building shaped tall and square, in the middle there is a furnace and above the stove there are two stacks of para-para, which function, in the first layer is used as a place to store food used during their stay, while in the second layer is under the roof roof tops or carried ridges functioned as offerings in the form of twigs from plants or stems and stems were given a spell that is believed to be able to repel intruders and will bring disaster to Tokaili and is called a sacred space. At this stage the concept of a microcosm in the "Kaili" society began to take shape.

Further developments show that "To Kaili" views the development of knowledge as evidenced by changes in behavior from meeting needs only from changing nature by meeting the needs of cultivation, this condition occurs as a result of the arrival of migrants from outside. Celebes Island, which by John Kruff, Kudern W explained that the "To Kaili" population which they called Toraja was influenced by migrants who came in two stages. The first stage migrants come through the Gulf of Bone then enter through the "Saddang" river, some live on the banks of the "Saddang" River and settle there named "SaddangToraja", the rest continue to the middle to Lore then occupy the area around the Koro river called Koro Toraja, the second stage migrants come from "Minahasa" Gorontalo then moved to Lore and continued to West Sulawesi they stopped at the Palu river called Palu Toraja, several others moved and arrived at the river bank called Poso "Torajaposo". The first stage of migration brought rock culture and the second stage of migration brought pottery, when this migration was carried out by John Kruif not explained (Kaudern, 1925).

When To Kaili develops an active lifestyle, they also develop life in the community and start when they live in a low realm which they call "Balingkae" and form a village (Boya), "Boya" is the development of "Ball" and "Bolanoa "Button. The ball used to be a gathering place and Totua's residence made a sacred place called "Lobo", if in the valley there is a valley in the middle of the valley which will be named duhunga. If the valley is in the valley on the hills at the top, it is called Baruga. If on the beach the name difference is influenced by the location of the house and the To Kaili settlement.

At that time "Totua" occupied Bolawo, thus forming a "Boya" consisting of one "Lobo", one "Bolawo" and several "Bolanoa", then supplemented with "gampiri" (granaries) which showed the development of small settlement patterns (nuclear family) into several families (extended families) f. The site "Boya" which is still found in its tracks and becomes the first "Boya" can be found in the village of Toro, Kulawi sub-district.

The Boya formed has a trench boundary inside the trench planted with bush and bamboo plants so that animals cannot enter into the "Boya" (Zaenal, 2013). "Boya" has one entrance as an access that residents use in and out. See the picture below.

The Boya shape pattern shows the presence of cosmology concept in the form of micro cosmos into the house building and also into the village formed by Lo- 
bo as the center of their ritual implementation as well as the center of decision making by Totua, the form of Lobo building replica see Figure 3 .

Several types of buildings have a very important value in the life of the To Kaili community. These buildings are Lobo which functions as a gathering place for family groups to hold rituals to the natural authority, lobo shape like Figure 4 .

Bolanoa Building shape Form is a simple building consisting of one space, currently Bolanoa building is usually used in the garden or in rice fields, see Figure 5.

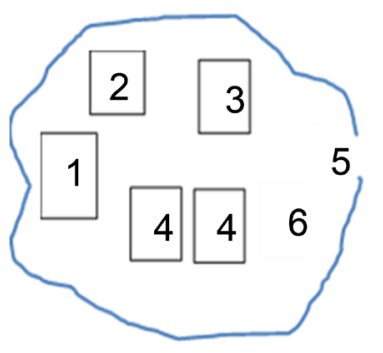

Legend:
1. Lobo
2. Gampiri
3. Bolawo
4. Bolanoa
5. Gate
6. Ditch

Figure 3. The shape pattern of the first kampong (Boya). Source: Researcher study conclusion.

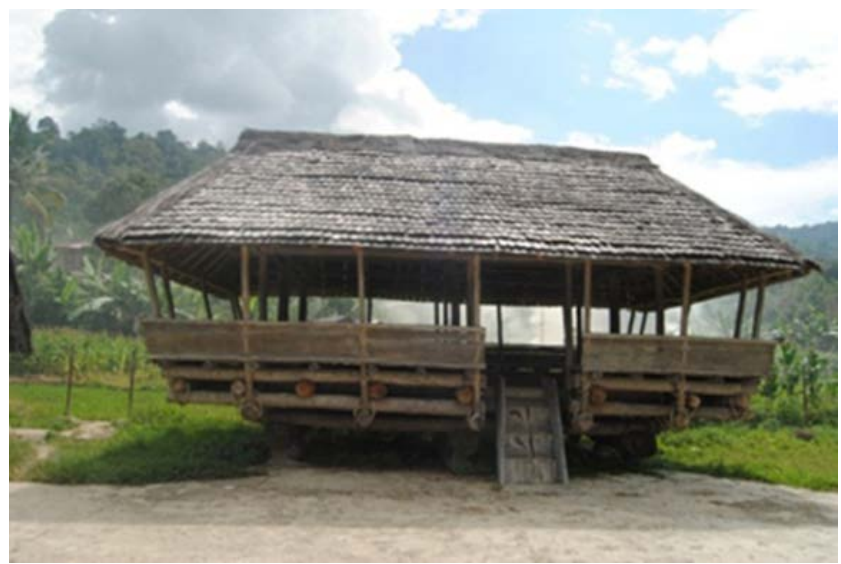

Figure 4. Building replica of Lobo in toro village. Source: Researcher documentation result 2013.

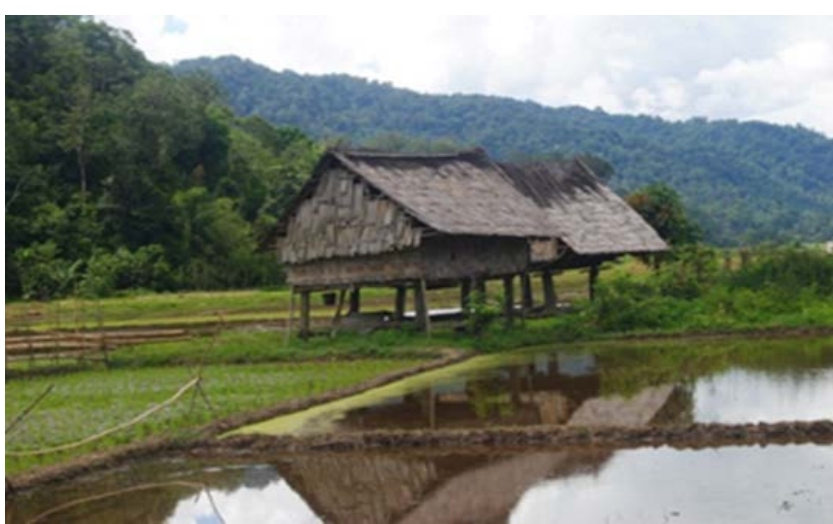

Figure 5. Bolanoa replica on the rice field. Source: Researcher documentation 2013. 
The rapid development of To Kaili culture led To Kaili to develop a village (Ngata). Ngata is a collection of Boya who have kinship ties, so usually in a village consisting of one family that has a lineage through a girl, this is because in the community Kailithrives exogamy marriage system where women are not allowed to marry the family, and women are not allowed to leave village.

In each village the number of heads of households grew to become more one and each head of the family should be represented in Totua, so that the number of Totua more than one, at this stage formed customary institutions consisting of several Totua as collective leaders and began to form customary rules, rules relating to Nature Guardian, such as the various rituals of birth and death as well as the ritual to ward calamities, and the ritual of disease treatment (nobalia).

Ngata developed into Ngata bête. The development of government that became the forerunner of the kingdom and its territory became very widespread because it is a merger of several Ngata that can be located far apart and formed the center of government consisting of: Jagugu as a ritual leader, Tina Ngata as the leader of women who have a village, Maradika as community leaders and Pabicara is the spokesman of news. Equipped with Totua which is a representative of each Ngata incorporated therein.

In Ngata bete, the concept of cosmology is also embedded, so the sacred center located in Ngata bête is located at the center of government, where in it there is Lobo as a place of worship as well as a place of lusting the case, Baruga as community meeting place and Gampiri as Ngata bête granary equipped with alunalun the gathering place of the whole community when it's harvesting party (Mopunca), or other ritual activities.

In the arrival of the kingdom influence originating from South Sulawesi that impacting on Ngata bête transformation into the kingdom and at that time happened acculturation of culture where in the community To Kaili previously not familiar with rice farming was introduced by migrants who come from neighboring areas and also introduced a new social stratum that is nobility.

The transformation from Ngata bête into several kingdoms in society of To kaili begins with the development of To Manure myth which explains the origins of their leaders as well as with the development of the term Tadulako which is defined as a mighty and always help the community, but not desire to become a ruler, the presence Tadulako in the To Kaili society has had a major impact on the habits of the former To Kaili community (warfare) (Mattulada, 1988). Pengayuan is a habit of the to Kaili leaders to prove his supernatural power in the past.

\subsection{Custom Concept (Vaya)}

The developmental dynamics of Tokaili in finding the equilibrium point in the settlement is marked by the various customary rules used to organize family life, in the community. The rules of custom rules govern things such as human relationships with human beings, human relationships with Nature Guardian and human relationships with nature and the environment, customary rules formed 
during the life of nomaden, which exercised, but they have a very important role when home and the settlement develops into a complex.

To Kaili undergoes a very complex process of development, when they decide to settle down in the settlement and the settlement develops along with the development of their culture, the development of the culture is the impact of the influx of migrants from outside and from the surrounding area, affecting the pattern of life and location setting settlement. This influence gave To Kaili the power to fight against the rule that had previously been a territory. In order for Tokaili to live a quiet life, it is agreed that there are rules that require various rituals as a form of compromise with the nature Guardian take it.

The emergence of various rituals which are the efforts of To Kaili fortify themselves from various possible disasters, requires the conduct of life cycle rituals such as birth rituals, death rituals and various rituals associated with life during adulthood such as rituals performed to treat diseases (nobalia), rituals performed to determine/avoid the occurrence of inbreeding (basiga).

The presence of these rituals indicates that To Kaili in his attempt to find the Equilibrium of life cannot be separated from the presence of Nature Guardian in every step of their lives. The life dynamics of To Kaili that are not separated from the presence of Nature Guardian in every step, are also reflected in the change of attitude in viewing the Nature guardian, when migrants come with different cultures and beliefs, so in some areas the influence of migrants from To Kaili causes a change in understanding and belief in Nature Guardians, for example when migrants coming from the kingdom of Bone and Gowa bring new beliefs about the existence of To Manurung which is sourced from the heavens and descended to earth to become their leader, this gives rise to myths about To manurung among To Kaili as well when Islamic prolityzer came to the To Kaili area to influence the existing customary rules.

\section{Conclusion}

Pehakovia is a cosmological concept embraced by Tokaili and became the basic principle that guides To Kaili in their lives. The cosmological concepts in society are related to space, place, and the establishment of houses and settlements. The dynamics of the development of cosmological concepts related to pehakovia shows the stages of the process that influences the development of Tokaili $s$ belief in developing human relationships with Nature Guardian.

The process of housing development and settlements associated with Pehakovia shows the intervention of migrants from outside the island of Celebes, and also the intervention of migrants from the island environment of Celebes greatly influences the development of beliefs and faith of to Kaili, so that the shifts in the values found in pehakovia undergo changes causing To Kaili to escape from a closed (exclusive) lifestyle into an open life, as seen in the process of house formation and settlement process taking place in To Kaili society. Thus, only with the process of changing from an endo game marriage system to an exo 
game marriage can make the community into an open, accepting society progress over time.

\section{Conflicts of Interest}

The author declares no conflicts of interest regarding the publication of this paper.

\section{References}

Dalsgaard, P. (2014). Pragmatism and Design Thinking. International Journal of Design, $8,143-155$.

Doxiadis, C. A. (1971). Ekistics, an Introduction to the Science of Human Settlements. Norwell, MA: Anchor Press.

Fathy, H. (1973). Architecture for the Poor, an Experiment in Rural Egypt. Chicago, IL and London: University of Chicago Press. https://doi.org/10.7208/chicago/9780226239149.001.0001

Healey, P. (2009). The Pragmatic Tradition in Planning Thought. Journal of Planning Education and Research, 28, 277-292.

Holden, M. (2008). The Tough Minded and the Tender Minded: A Pragmatic Turn for Sustainable Development Planning and Policy. Journal of Planning Theory and Practice, 9, 475-496. https://doi.org/10.1080/14649350802481371

Kaudern, W. (1925). Ethnographical Studies in Celebes: Results of the Author's Expedition to Celebes, 1917-1920. Translated by Fru Teres Andersson Kaudern, Volume 4.

Oliver, P. (1997). Dwellings, the House across the World. Oxford: Phaidon Press Limited, Littlegate House, St Ebber's.

Rapoport, A. (1969). House Form and Culture. Englewood Cliffs, NJ: Prentice-Hall.

Rapoport, A. (1977). Human Aspect of Urban Form. Oxford: Pergamon Press.

Simanjuntak, T. (2008). Austronesian in Sulawesi. Jakarta: Center for Prehistoric and Austronesian Studies.

Mattulada (1988). Andi, to Kaili. Kota Palu: Penerbit United Press.

Zaenal (2013). Pola Bermukim to Kaili di Sulawesi Tengah, Prosiding Seminar Nasional, Reinterpretasi Identitas Arsitektur Nusantara, penerbit Universitas Udayana, 2013 Bali.

Zaenal (2014). Hintuvu Concept on Settlement to Kaili in Central Sulawesi. In International Conference on Sustainable Environmental Architecture (p. 17). Makassar: Department of Architecture Faculty of Hasanuddin University.

Zaenal (2015). Hirarki dan keterhubungan Sou, Boya, Ngata, Ngata Bete pada pemukiman Masyarakat to Kaili. Disertasi S3 Arsitektur, Ugm, 2015.

Zaenal (2016). Re Articulation of Indigenous Bajo in Build Home, Case Village Kabalutan. In International Seminar on Vernacular Settlements (p. 18). Makassar: Department of Architecture Faculty of Engineering Hasanuddin University. 